\title{
Hyperinsulinemia in Obese and Non-Obese Young Japanese Hypertensive Men
}

\author{
Hiroshi Kawabe, Ikuo Saito, Motoko Nishino, Hideki Wainai, Shiro Nagano, and Takao Saruta*
}

\begin{abstract}
We investigated whether hyperinsulinemia and insulin resistance were associated with hypertension independent of obesity in young (mean age 20 years) Japanese men. Subjects were classified as hypertensive if their systolic or diastolic blood pressure (BP) was $\geq 140$ or $\geq 90 \mathrm{~mm} \mathrm{Hg}$, respectively. Subjects were classified as obese if their body mass index (BMI) was $\geq 26$. We divided 88 subjects into four groups: 29 nonobese normotensives (NONT), 12 nonobese hypertensives (NOHT), 28 obese normotensives (ONT), and 19 obese hypertensives (OHT). We conducted a $75 \mathrm{~g}$ oral glucose tolerance test (OGTT) and measured plasma glucose and serum insulin at 0,30 , and $60 \mathrm{~min}$. We found similar glucose levels at fasting and during OGTT in all groups. Compared with the NONT group, the insulin levels at fasting and during OGTT were significantly higher in the NOHT group. No difference was found between the NOHT and ONT groups. The glucose/insulin ratios and the ratio of glucose area to insulin area were significantly lower in the NOHT group than in the NONT group; no difference was found between the NOHT and ONT groups. The OHT group had higher fasting insulin levels and lower fasting glucose/insulin ratios than the NOHT or ONT group. The fasting glucose/insulin ratio was correlated with the mean BP when the normotensives and hypertensives were combined. In a multiple regression analysis including BMI, the mean BP was still significantly related to the fasting glucose/insulin ratio. Our data indicate that hyperinsulinemia is associated with hypertension and is independent of obesity in young Japanese men. (Hypertens Res 1994 ; 17 : 133-136)
\end{abstract}

Key Words: glucose/insulin ratio, glucose tolerance test, hyperinsulinemia, hypertension, obesity

For many years, it has been recognized that hypertension is common in obese people, especially in middle-aged individuals $(1,2)$. Because overweight or hypertensive subjects, or both, have been found to be insulin-resistant compared to normal subjects $(3-5)$, it has been hypothesized that insulin or insulin resistance, or both, may be a factor linking obesity with hypertension $(6,7)$. However, it is not yet clear whether young Japanese nonobese subjects with hypertension are more insulin-resistant than young nonobese or obese normotensive subjects. In the present study, we compared multiple indices of glucose and insulin in young obese and nonobese normotensive and hypertensive subjects.

\section{Methods}

Subjects

The subjects, 88 Japanese male students with a mean age of $20 \pm 1$ years (range 16-24 years), were selected during an annual school health examination. Thirty-one subjects were classified as hypertensive: their blood pressure (BP) was above $140 \mathrm{mmHg}$ systolic or $90 \mathrm{mmHg}$ diastolic, or both, as measured by a physician on three separate visits. A complete medical work-up was done to exclude secondary forms of hypertension. At the time, no subject was being treated with antihypertensive medication. Fifty-seven subjects with systolic BP less than $140 \mathrm{mmHg}$ and diastolic BP less than 90 $\mathrm{mmHg}$ were classified as normotensive. Forty-seven subjects whose body mass index (BMI, weight / height $^{2}$, in kilograms / square meter) was greater than 26 were classified as obese. The subjects were divided into four groups: nonobese normotensives (NONT, $n=29$ ), nonobese hypertensives (NOHT, $n$ $=12$ ), obese normotensives (ONT, $n=28$ ), and obese hypertensives (OHT, $n=19$ ). Baseline data for the four groups are given in Table 1. The groups were matched in age and height, except that subjects in the NONT group were slightly older than those in the ONT group. Both hypertensive (NOHT and OHT) and obese (ONT and OHT) groups were matched for BP or BMI, respectively. Also, both normotensive (NONT and ONT) and nonobese (NONT and NOHT) groups were matched for BP or BMI, respectively. There were no differences in the incidence of positive family history of hypertension or diabetes mellitus among the four groups. Each subject gave his informed consent to a protocol previously approved by our institution's review committee.

From the Health Center, Keio University, ${ }^{*}$ Department of Internal Medicine, School of Medicine, Keio University. Tokyo, Japan.

Address for Reprints: Hiroshi Kawabe, M.D., Health Center, Keio University, 35 Shinanomachi, Shinjuku-ku, Tokyo 160, Japan.

Received November 10, 1993; accepted in revised form March 18, 1994. 
Oral Glucose Tolerance Test

At 9:00 AM, after the subjects had fasted 10 to 12 h overnight, we did a standard oral glucose tolerance test (75-g OGTT) and measured plasma glucose and serum insulin concentrations during fasting, and 30 and 60 min after glucose ingestion. Plasma glucose was measured by the glucose-oxidase method. Serum insulin levels were measured by radioimmunoassay.

\section{Statistical Analysis}

Values are expressed as mean \pm SEM. To examine the statistical significance of differences between the four groups, ANOVA and Scheffe's multiple comparison tests were done. Student's $t$-test or the Wilcoxon matched-pairs signed rank test were also used for paired comparisons. Correlations were estimated by linear regression analysis. The analysis of the relationships between the fasting plasma glucose/ serum insulin ratio, mean $\mathrm{BP}$, and $\mathrm{BMI}$ was done with multiple regression. Differences were considered statistically significant when $p<0.05$.

\section{Results}

75-g OGTT (Fig. 1)

Subjects whose fasting glucose was $\geq 6.1 \mathrm{mmol} / 1$ $(110 \mathrm{mg} / \mathrm{dl})$ and whose glucose at $60 \mathrm{~min}$ was $\geq 8.9$ $\mathrm{mmol} / \mathrm{l}(160 \mathrm{mg} / \mathrm{dl})$ were not included in this study. Plasma glucose during fasting and during OGTT were normal and the values were similar for all four groups. Serum insulin concentration during fasting was significantly higher in the NOHT group $(77.8 \pm$ $10.3 \mathrm{pmol} / 1)$ than in the NONT group $(39.8 \pm 2.7$ $\mathrm{pmol} / \mathrm{l})$. The fasting insulin in the OHT group $(146.5 \pm 16.5 \mathrm{pmol} / \mathrm{l})$ was significantly higher than in the other three groups. However, no difference in serum insulin was seen between the NOHT and ONT $(98.4 \pm 8.4 \mathrm{pmol} / \mathrm{l})$ groups. In response to glucose, the serum insulin concentration rose to significantly higher peaks in the NOHT group than in the NONT group; no difference was observed between the NOHT and the ONT groups. Although serum insulin levels at 30 and $60 \mathrm{~min}$ were similar in the two obese groups, the OHT group had a higher insulin level at $60 \mathrm{~min}$ than the NOHT group.

\section{Indices of Glucose and Insulin}

The fasting plasma glucose/serum insulin ratio $(\mathrm{G} / \mathrm{I}$ ratio) was significantly $(p<0.01)$ lower in the NOHT group $(0.067 \pm 0.008)$ than in the NONT group $(0.133 \pm 0.008)$. There was no difference between the NOHT group and the ONT group $(0.057$ $\pm 0.006)$. The OHT group $(0.041 \pm 0.005)$ had a lower fasting G/I ratio than the ONT group. Similar patterns were observed in the $\mathrm{G} / \mathrm{I}$ ratios at 30 and 60 min during the OGTT in all the groups (data not shown). The ratios of plasma glucose area to serum insulin area, determined by calculating the areas under the concentration curves, were also significantly $(p<0.01)$ lower in the NOHT group $(0.019$ $\pm 0.003)$ than in the NONT group $(0.038 \pm 0.003)$. No difference was found among the NOHT and the two obese groups (ONT: $0.014 \pm 0.001$, OHT: 0.013
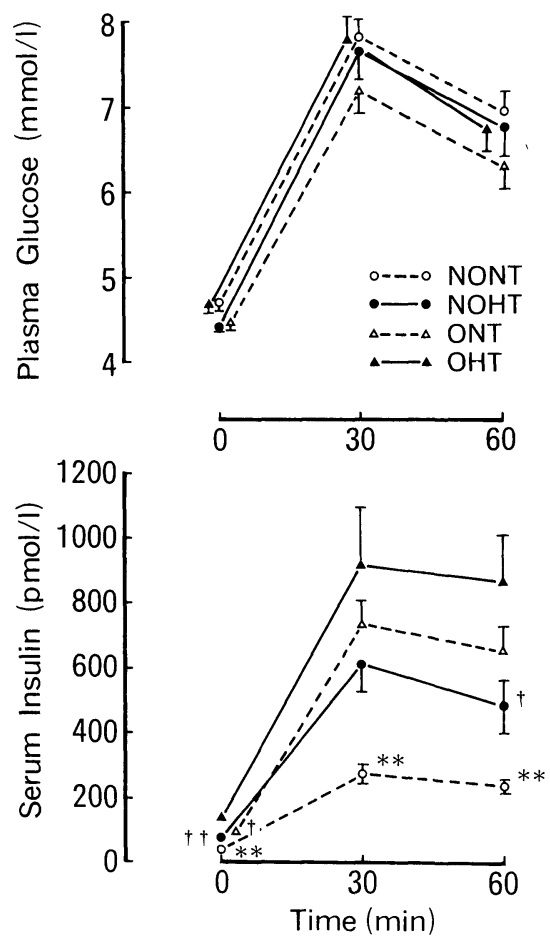

Fig. 1. Plasma glucose and serum insulin levels during 75 $g$ oral glucose tolerance test in four groups. NONT, nonobese normotensive $(\mathrm{n}=29)$. NOHT, nonobese hypertensive $(\mathrm{n}=12)$. ONT, obese normotensive $(\mathrm{n}=28)$. OHT, obese hypertensive $(\mathrm{n}=19)$. ${ }^{* *} \mathrm{p}<0.01$ when compared with all other groups. ${ }^{\dagger} \mathrm{p}<0.05,{ }^{\dagger \dagger} \mathrm{p}<0.01$ when compared with the OHT group.

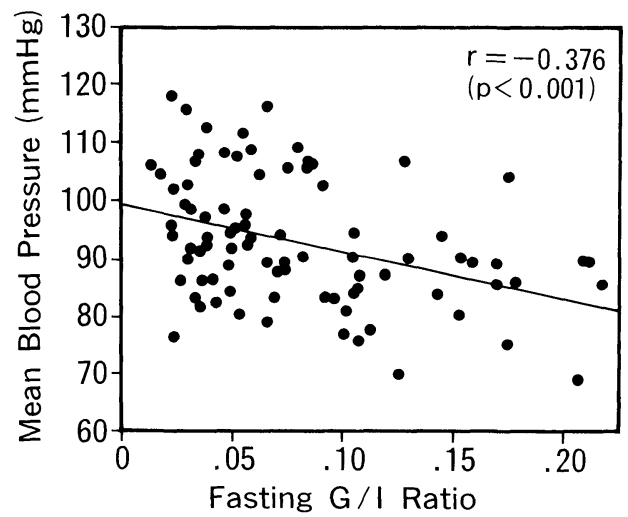

Fig. 2. Correlation between fasting plasma glucose (G) / serum insulin (I) ratio and mean blood pressure in all subjects $(\mathrm{n}=88)$.

$\pm 0.002)$

The fasting $G / I$ ratio was correlated with the mean BP when normotensives and hypertensives were combined (Fig. 2). In a multiple regression analysis of data from all the subjects, the mean BP and BMI were both significantly related to the fasting $\mathrm{G} / \mathrm{I}$ ratio $(F=35.057, d f=2,85, p<0.0001)$. We obtained the following equation: fasting $\mathrm{G} / \mathrm{I}$ ratio= 
Table 1. Clinical Characteristics of the 88 Subjects

\begin{tabular}{lcccc}
\hline & $\begin{array}{c}\text { NONT } \\
(n=29)\end{array}$ & $\begin{array}{c}\text { NOHT } \\
(n=12)\end{array}$ & $\begin{array}{c}\text { ONT } \\
(n=28)\end{array}$ & $\begin{array}{c}\text { OHT } \\
(n=19)\end{array}$ \\
\hline Age (years old) & $20.3 \pm 0.2^{*}$ & $19.6 \pm 0.6$ & $18.6 \pm 0.5$ & $19.9 \pm 0.5$ \\
Height $(\mathrm{cm})$ & $171.4 \pm 1.2$ & $170.5 \pm 2.1$ & $170.6 \pm 1.0$ & $173.3 \pm 1.6$ \\
Body weight $(\mathrm{kg})$ & $64.1 \pm 1.3^{\dagger \dagger}$ & $65.4 \pm 2.2^{\dagger \dagger}$ & $86.6 \pm 1.5$ & $92.9 \pm 2.7$ \\
BMI $\left(\mathrm{kg} / \mathrm{m}^{2}\right)$ & $21.8 \pm 0.4^{\dagger \dagger}$ & $22.5 \pm 0.6^{\dagger \dagger}$ & $29.7 \pm 0.4$ & $31.0 \pm 0.6$ \\
SBP (mmHg) & $125 \pm 2$ & $149 \pm 2^{\ddagger \ddagger}$ & $123 \pm 2$ & $146 \pm 1^{\ddagger \ddagger}$ \\
DBP (mmHg) & $67 \pm 1$ & $85 \pm 2^{\ddagger \ddagger}$ & $71 \pm 2$ & $81 \pm 3^{\ddagger \ddagger}$ \\
\hline
\end{tabular}

Values are mean \pm SEM. ${ }^{*} p<0.05$ when compared with obese normotensive (ONT) group. ${ }^{\dagger \dagger} p<0.01$ when compared with ONT and obese hypertensive (OHT) groups. ${ }^{\ddagger \ddagger} p<0.01$ when compared with nonobese normotensive (NONT) and ONT groups. NOHT, nonobese hypertensive. BMI, body mass index. SBP, systolic blood pressure, DBP, diastolic blood pressure.

$0.369-0.006$ (BMI) - 0.001 (mean BP), in which both regression coefficients were statistically significant $(p<0.005)$.

\section{Discussion}

In this study, we found that nonobese young hypertensive subjects had higher basal and stimulated-insulin levels, a lower fasting G/I ratio, and a lower ratio of plasma glucose area to serum insulin area than did their age- and BMI-matched normotensive counterparts. These four variables were similar in nonobese hypertensive subjects and obese normotensive subjects. There was a significant correlation between the fasting G/I ratio and the BP, which was independent of the subjects' BMI.

Fasting glucose concentration depends primarily on the rate of hepatic glucose release, which in turn is regulated by insulin concentration. Therefore, the fasting $\mathrm{G} / \mathrm{I}$ ratio provides an estimate of insulin resistance $(8)$. We know that the glucose clamp technique, the minimal model technique, or the steadystate plasma glucose method is better for evaluating the state of insulin resistance than OGTT. However, OGTT was the only method we could do in these young students. Since Caro (8) reported that $\mathrm{G} / \mathrm{I}$ ratio correlated with the results of the glucose clamp, we used it as an index of sensitivity to insulin in this study.

We confirmed previous observations that obese hypertensive subjects are more hyperinsulinemic than obese normotensive subjects, and that obese subjects are more hyperinsulinemic than nonobese subjects $(9,10)$. Furthermore, we found that young nonobese hypertensive subjects are more hyperinsulinemic than nonobese normotensive subjects. In fact, their hyperinsulinemic state is comparable to that of obese normotensive subjects. A similar observation of middle-aged (mean age 49 years) white subjects was made by Sechi, et al. (11). They showed that, when compared to lean normotensive subjects, overweight normotensive, lean hypertensive, and overweight hypertensive subjects had significantly higher fasting insulin levels and lower $G / \mathbf{I}$ ratios. Another author referred to, however, racial differences in the relation between insulin resistance and BP (12). Our data, collected from young (mean age 20 years) Japanese men, shows hyperinsulinemia in nonobese hypertensive subjects.

Previously, we demonstrated a correlation between levels of physical activity and the fasting G/I ratio in young obese students (13). It has been demonstrated that tissue insulin sensitivity improves when obese subjects engage in vigorous physical activity, even with minimal changes in body weight (14). Furthermore, the fasting G/I ratio was correlated with BP and was independent of body weight in this study. Although this suggests that physical training could lower BP by improving insulin sensitivity, further studies will be needed to establish a cause-and-effect relationship.

In conclusion, our data indicate that hyperinsulinemia is associated with hypertension and is independent of obesity in young Japanese men. We suggest that young nonobese hypertensive subjects are already more resistant to insulin than age- and BMI-matched normotensive subjects, and that their insulin-resistant state is comparable to that of obese normotensive subjects.

\section{References}

1. Modan M, Halkin H, Almog S, et al: Hyperinsulinemia: a link between hypertension, obesity and glucose intolerance. J Clin Invest 1985 ; 75 : 809-817.

2. Havlik RJ, Hubert HB, Fabsitz RR, Feinleib M: Weight and hypertension. Ann Intern Med 1983 ; 98 : 855-859.

3. Bonadonna R, Groop L, Kraemer N, DeFronzo RA: Obesity and insulin resistance in man: a dose response study. Metabolism $1990 ; 39$ : 452-459.

4. Kolterman OG, Insel J, Saekow M, Olefsky JM: Mechanism of insulin resistance in human obesity: evidence for receptor and post-receptor defects. $J$ Clin Invest $1980 ; 65: 1273-1284$.

5. Ferrannini E, Buzzigoli G, Bonadonna R, et al: Insulin resistance in essential hypertension. $N$ Engl $J$ Med $1987 ; 317: 350-357$.

6. Singer P, Gödicke W, Voigt S, Hajdu I, Weiss M: Postprandial hyperinsulinemia in patients with mild essential hypertension. Hypertension 1985 ; 7 : 182186.

7. Reaven GM, Hoffman BB: A role for insulin in the aetiology and course of hypertension? Lancet 1987 ; ii : $435-437$. 
8. Caro JF: Insulin resistance in obese and nonobese man. J Clin Endocrinol Metab 1991 ; 73 : 691-695.

9. Manicardi V, Camellini L, Bellodi G, Coscelli C, Ferrannini E: Evidence for an association of high blood pressure and hyperinsulinemia in obese man. $J$ Clin Endocrinol Metab 1986 ; 62 : 1302-1304.

10. Rocchini AP: Insulin resistance and blood pressure regulation in obese and nonobese subjects. Hypertension $1991 ; \mathbf{1 7}: 837-842$.

11. Sechi LA, Melis A, Pala A, Marigliano A, Sechi G, Tedde R: Serum insulin, insulin sensitivity, and erythrocyte sodium metabolism in normotensive and essential hypertensive subjects with and without overweight. Clin Exp Hypertens 1991 ; A13 : 261-276.

12. Saad MF, Lillioja S, Nyomba BL, et al: Racial differences in the relation between blood pressure and insulin resistance. $N$ Engl J Med $1991 ; 324$ : 733-739.

13. Saito I, Nishino $\mathrm{M}$, Kawabe $\mathrm{H}$, et al: Leisure time physical activity and insulin resistance in young obese students with hypertension. Am J Hypertens $1992 ; 5$ : 915-918.

14. Björntorp P, DeJounge K, Sjöström L, Sullivan L: The effect of physical training on insulin production in obesity. Metabolism 1970; 19 : 631-638. 